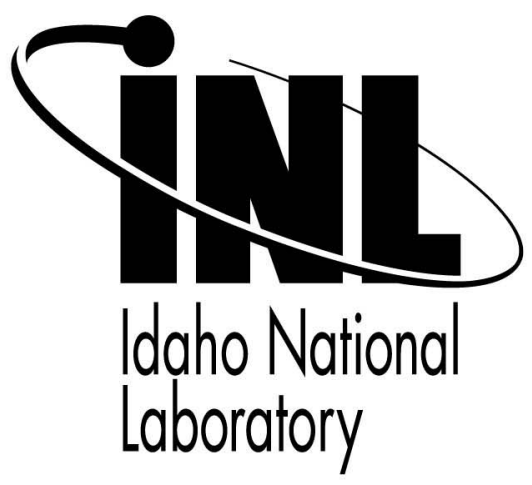

\title{
Cognitive Virtualization: Combining Cognitive Models and Virtual Environments
}

\section{Joint $8^{\text {th }}$ IEEE HFPP $/ 13^{\text {th }}$ HPRCT}

Tuan Q. Tran

David I. Gertman

Donald D. Dudenhoeffer

Ronald L. Boring

Alan R. Mecham

\section{August 2007}

This is a preprint of a paper intended for publication in a journal or proceedings. Since changes may be made before publication, this preprint should not be cited or reproduced without permission of the author. This document was prepared as an account of work sponsored by an agency of the United States Government. Neither the United States Government nor any agency thereof, or any of their employees, makes any warranty, expressed or implied, or assumes any legal liability or responsibility for any third party's use, or the results of such use, of any information, apparatus, product or process disclosed in this report, or represents that its use by such third party would not infringe privately owned rights. The views expressed in this paper are not necessarily those of the United States Government or the sponsoring agency. 


\title{
Cognitive Virtualization: Combining Cognitive Models and Virtual Environments
}

\author{
Tuan Q. Tran, David I. Gertman, Donald D. Dudenhoeffer, Ronald L. Boring, \& Alan R. Mecham
}

Human Factors and I\&C Systems Department, Idaho National Laboratory, Idaho Falls, ID, USA.

\{tuan.tran, david.gertman, donald.dudenhoeffer, ronald.boring, alan.mecham\}@inl.gov

\begin{abstract}
D manikins are often used in visualizations to model human activity in complex settings. Manikins assist in developing understanding of the range, scope and timing of various human activities. They are applicable to a wide range of environments.. One such environment, the nuclear power plant control room, is a setting where manikins can be used to simulate more precise ergonomic assessments of human work stations. Next generation control rooms will pose numerous challenges for system designers. The manikin modeling approach by itself, however, is insufficient for dealing with the technical advancements and performance demands associated with proposed next generation control rooms. Uncertainty regarding effective staffing levels; and the potential for negative human performance consequences in the presence of advanced automated systems (e.g., reduced vigilance, poor situation awareness, mistrust or blind faith in automation, higher information load and increased complexity) call for further research. One approach to managing design uncertainty is through complementary analysis that merges ergonomic manikin models with models of higher cognitive functions, such as attention, memory, decision-making, and problem-solving. This paper will discuss recent advancements in merging a theoretical-driven cognitive modeling framework within a 3D visualization modeling tool to conduct next generation control room human factors and ergonomic assessments. Though this discussion primary focuses on control room design, merging 3D visualization and cognitive modeling can be extended to various areas of focus such as training and scenario planning.
\end{abstract}

\section{INTRODUCTION}

Next generation control rooms are anticipated be more computerized, intelligent, integrated, and automated, thus shifting the operator's role to more of a supervisory control with emphasis on monitoring. Automation when implemented without careful planning, can sometimes lead to "clumsy" automation, a tendency of automation to make task execution easy and simple during normal operation situations but more difficult during off-normal or unanticipated events, with the latter resulting in high task-load [1]. High task-load is known to induce stress as well as fatigue, while vigilance is recognized to drop drastically after $30 \mathrm{~min}$ of prolonged monitoring [2]. Interactively, these factors can severely diminish one's ability to perceive, recognize, and respond to emergency or unanticipated events and, thus, can place both the operator and system at risk.

The extent of change to the operating environment and the operator's role is extensive. Compared to today's operating paradigm, the operational, safety, and performance requirements for next generation control rooms with increased automation will change in regards to:

- Plant staffing model and roles;

- Information presentation, complexity and integration;

- System automation and levels of operator responsibility;

- Operating and maintenance procedures; and

- Training and qualification.

For these reasons, we feel the ability to simulate human behaviors in a wide-array of novel or untested environmental context is essential in planning and developing human factors design interfaces for next generation control rooms to ensure plant safety.

Currently, there is no established model of individual or team performance in the nuclear domain. There are no requirements for using simulation to assess the impact of design changes. Human reliability analysis (HRA) methods [3] detail a number of performance shaping factors considered in predicting human error probability estimates (HEPs). Potentially, HRA could be used to analyze the impact of human performance in automated worlds. However, HRA methods do not predict whether one type of error within a particular class of errors is more likely than another or why. This is because the methods have been developed for risk analysis purposes, and underlying models of cognition per se, are not computationally extensive. Typically, "what if" scenarios are examined on the task level and cognition is modeled on the basis of task requirements and performance shaping factors.

To date, very few attempts have been undertaken to explore the use of HRA as a design tool [4]. Thus, performance modeling, as practiced in the nuclear domain, is not pure behavioral modeling and has not been informed by the most recent theoretical advances. The opportunity exists to: learn from advances in these general performance models for complex tasks, exploit what is known about error and its impact in nuclear environments, and thus, contribute to the safety and operational excellence of next generation reactors. This paper will discuss recent advancement in merging a theoretical-driven cognitive modeling framework within a $3 \mathrm{D}$ visualization modeling tool for evaluation of next generation control room human factors and ergonomic assessment. 


\section{STATE OF ART IN PERFORMANCE MODELING}

Cognitive modeling has been an increasingly popular approach in aviation, military, and process industries, for its computational power to simulate human information processing [5] in relation to:

- How humans interact with novel and advanced technology (e.g., vigilance, decision-making)

- Identifying and predicting risk and error performance

- Understanding "how" and "why" errors occurred

- Evaluating individual workload

- Determining appropriate staffing models and roles

- Addressing team/crew situation awareness, collaboration, and performance

- Simulating "What if" scenarios to increase explanatory power.

Currently, there are numerous cognitive modeling approaches, each with its strengths and weaknesses as well as its alliance to a particular theoretical perspective. Table 1 presents a list of major cognitive modeling approaches that are currently employed in the behavioral sciences. The models in Table 1 are order in magnitude of high-level human performance (top of the Table) to low-level human performance (bottom of the Table). As Table 1 illustrates, there is currently no "magical" bullet in cognitive modeling, that is, a perfect model that can stimulate human cognition across a broad range of human behaviors.

For instance, ACT-R and SOAR are a strong cognitive modeling approaches beneficial in understanding and predicting memory errors (e.g., slips, lapses, and mistakes) but are fairly under-developed in understanding human-machine interaction at high-level as it pertains to crew performance. Their utility lies in well developed explanatory power in regards to lower level cognitive behavior. MIDAS, EPIC, and Task Network models have been demonstrated to be effective approaches in modeling human-machine interaction and crew performance but lack a strong theoretical stance to understand how such behaviors emerged from the lower-level cognitive processes to influence behavior. Finally, GLEAN is well-suited in understanding user's procedural knowledge of a system but lacks a strong explanatory power in understanding low-level cognitive processes as well as high-level human-machine interaction. The strengths and weaknesses within each modeling approach place a heavy constraint upon researchers who are interested in examining a broad range of cognitive behaviors, from memory retrieval errors to multitasking performance. The state of art in cognitive modeling forces researchers to choose among competing models and to accept the strengths as well as its weaknesses associated with the selected model.

Finally, the state of art of performance modeling in the behavioral sciences including cognitive modeling does not fully support ergonomic concerns. Computer generated 3-D manikins are currently used to assist in understanding human actions, movements and routines in a variety of different environments for conceptual design evaluation A few cognitive models (e.g., the manikin "JACK" in MIDAS) have integrated manikins in their modeling simulations. However, these models lack adaptability and a transparent cognitive theory to drive certain behaviors such as human errors (e.g., slips, laps, and mistakes)

TABLE 1. MAJOR COGNITIVE MODELING APPROACHES

\begin{tabular}{|c|c|c|c|}
\hline $\begin{array}{l}\text { Performance } \\
\text { Modeling }\end{array}$ & $\begin{array}{l}\text { Brief } \\
\text { Descriptions }\end{array}$ & $\begin{array}{l}\text { Primary } \\
\text { Strengths }\end{array}$ & $\begin{array}{l}\text { Primary } \\
\text { Weakness }\end{array}$ \\
\hline $\begin{array}{l}\text { MIDAS } \\
\text { (CORE/AIR) }\end{array}$ & $\begin{array}{l}\text { Midas is } \\
\text { designed to } \\
\text { assess high-level } \\
\text { human-system } \\
\text { interaction in } \\
\text { the complex, } \\
\text { dynamic } \\
\text { environments. }\end{array}$ & $\begin{array}{l}\text { Human- } \\
\text { Machine- } \\
\text { Interaction } \\
\text { and Crew } \\
\text { Performance }\end{array}$ & $\begin{array}{l}\text { Transparency } \\
\text { of Low-Level } \\
\text { Cognitive } \\
\text { Processes }\end{array}$ \\
\hline EPIC & $\begin{array}{l}\text { EPIC is } \\
\text { designed to } \\
\text { assess low-level } \\
\text { multi-tasking } \\
\text { performance }\end{array}$ & $\begin{array}{l}\text { Multi- } \\
\text { Tasking }\end{array}$ & $\begin{array}{l}\text { Low-Level } \\
\text { Cognitive } \\
\text { Processes }\end{array}$ \\
\hline Task Network & $\begin{array}{l}\text { Task Network is } \\
\text { designed to } \\
\text { model high-level } \\
\text { human } \\
\text { performance in } \\
\text { complex systems } \\
\text { via task } \\
\text { decomposition }\end{array}$ & $\begin{array}{l}\text { Multi- } \\
\text { Tasking and } \\
\text { Crew } \\
\text { Performance }\end{array}$ & $\begin{array}{l}\text { Cognitive } \\
\text { Processes }\end{array}$ \\
\hline GLEAN & $\begin{array}{l}\text { GLEAN is a } \\
\text { GOMS model } \\
\text { designed to } \\
\text { model low-level } \\
\text { human } \\
\text { interaction with } \\
\text { device or system }\end{array}$ & $\begin{array}{l}\text { Procedural } \\
\text { Behaviour }\end{array}$ & $\begin{array}{l}\text { Cognitive } \\
\text { Processes and } \\
\text { High-Level } \\
\text { Human- } \\
\text { Machine- } \\
\text { Interaction }\end{array}$ \\
\hline SOAR & $\begin{array}{l}\text { SOAR is a } \\
\text { cognitive } \\
\text { architecture that } \\
\text { can be use to } \\
\text { model low-level } \\
\text { cognitive tasks }\end{array}$ & $\begin{array}{l}\text { Reasoning, } \\
\text { Learning, } \\
\text { Problem- } \\
\text { Solving }\end{array}$ & $\begin{array}{l}\text { High-Level } \\
\text { Human- } \\
\text { Machine } \\
\text { Interaction }\end{array}$ \\
\hline ACT-R & $\begin{array}{l}\text { ACT-R is a } \\
\text { cognitive } \\
\text { architecture that } \\
\text { can be used to } \\
\text { model low-level } \\
\text { cognitive tasks }\end{array}$ & $\begin{array}{l}\text { Learning and } \\
\text { Memory }\end{array}$ & $\begin{array}{l}\text { High-Level } \\
\text { Human- } \\
\text { Machine- } \\
\text { Interaction } \\
\text { and Multi- } \\
\text { Tasking }\end{array}$ \\
\hline
\end{tabular}




\section{AN INTEGRATED PERFORMANCE MODELING APPROACH}

We propose an integrated performance modeling (IPM) approach leveraging the recent advancement in cognitive, ergonomic, and environmental modeling advancement to support research and design process of advanced and novel system design and configurations for next generation control rooms. Though this discussion may have as its primary focus control room design, the application for such a merger among different modeling approaches can be extended to various areas of focus such as training and scenario planning. The proposed IPM is a tripartite model; a modeling environment to capture advanced or novel system designs and configurations, a virtual 3D manikin model that not only captures ergonomic body-dimension (e.g., $5^{\text {th }}$ and $95^{\text {th }}$ percentile as well as special populations) but also behaviorally accurate algorithms (e.g., using Fitt's Law to determine movement time), and a mechanism to plug-and-play different cognitive models presented in Table 1 thought to drive different human behaviors. We next briefly discuss each model embedded within IPM.

\section{A. Modeling Environment}

To model the environmental context, IPM is planned to use the Critical Infrastructure Modeling Simulation Software Environment (CIMS) developed by [6]. CIMS, an object oriented model building tool and simulation environment was developed to allow scientists and research analysts the ability to bring together different simulations representing diverse infrastructure domains while providing a nodal network allowing these simulations to interact. CIMS provides a framework for the integration of nuclear plant simulation (the environment simulation), cognitive modeling simulation(s), and 3-D virtual interactive manikin modeling, i.e., the manikins interact with equipment and systems in a realistic fashion and the control actions they take provide input to the environment simulation resulting in changes in process parameters and plant conditions. The nodal networks underlying CIMS linked through simple point and click operation and act as individual agents with properties and priorities that are easily programmed.

Operation of CIMs software is familiar to users of GIS or GoogleEarth. Combined with powerful 3-D rendering and navigation, it allows for modeling and simulating complex behaviors, and predicts emergent behaviors through time, aspects of which will be employed in the present project. Scalability is another laudable attribute. CIMS can support analyst review of plant performance, procedural compliance, or individual operator task execution. Individual nodes can be keyed to either single or massed sensor input or piped in simulation data representing component or system response. Ability typical of the system includes presentation, interaction, and prediction of moving entities such as planes, trains, cars and people and timebased effects of their status on related structures, systems, components, and facilities. Multiple views of emergent situations are available and process-, performance- and procedures- interaction are supported by an event sequence planner. The event sequence planner was designed to integrate human interaction with infrastructure on a systems level and will be used to support integration of the cognitive model and 3D manikin actions with the environment simulation.

CIMs is capable of incorporating control room architecture, plant conditions, and plant interfaces upon which the manikin with its associated cognitive model can act.

\section{B. Modeling the Manikin}

When completed each manikin within the environment acts and react to the environment around them through either rule-based artificial intelligence (AI), cognitive model simulations, or scripted behavior. Through modular design of different sets of rules, models or scripts, model implementation is easyily and quickly changed to evaluate scenarios in many different ways. Since not every scenario will require emergent behavior or intelligent decision making, modularity will yield a higher coverage area of application.

Each manikin within the CIMS simulation will act independently. Manikins would be able to receive input and pass output to the environment and other manikins around it.

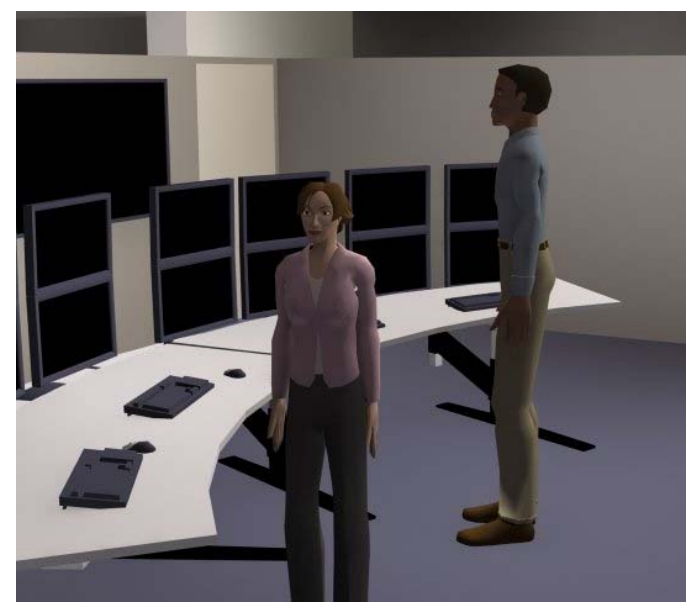

Figure 1. Sample of IPM virtual environment

Each manikin is treated as one of these nodes in the same way that all other assets within the simulation are handled. The manikin is be connected to other nodes which could be manikins, control room displays, or 
even infrastructure nodes that have no physical representation. When receiving input from these nodes the manikin processes the information that is presented and act upon it. Once the manikin has acted, it then sends state change information to the node or nodes that are affected by its actions. Manikins could therefore be used in numerous ways while maintaining CIMS's existing data structures and design strength.

\section{B. Modeling Cognition}

We propose that CIMS can provide an efficient and sufficiently robust platform for researchers to interface (i.e., plug-in) their cognitive model and to have that model interact with the environment simulation and manikin. The appropriate level of detail for cognitive modeling will be determined as a function of the human-system interaction scenario selected. The CIMS environment supports any combination of eventsequence modeling, task modeling, or detailed cognitive modeling. For instance, if the selected scenario involves a single, well understood, proceduralized set of control room tasks then a cognitive modeling approach such as GLEAN can be plugged into CIMS. If the selected scenario of interest emphasizes multitasking behaviors in a complex, rapidly changing environment, a strong multitasking cognitive modeling approach such as MIDAS, EPIC, or Task Nework can be employed. Finally, if the emphasis of the selected scenarios involves memory or problem-soving behaviors then ACT-R and SOAR would be the ideal selected approaches, respectively. Therefore, CIMS with its "plug-and- play" interface can maximize the number of modeling choices available to the analyst.

\section{ANTICIPATED BENEFITS AND APPLICATIONS OF IPM FRAMEWORK}

Next generation control rooms will pose numerous challenges such as:

- Human Reliability Analysis - challenges to identify and quantify human error probabilities associated with performance in advanced automation system

- Next-Generation Control Room Design challenges of evaluating and optimizing humansystem interaction with novel instrumentation and configurations

- Staffing Analysis - challenges in determining the ideal staffing model for next generation control room

- Training - challenges to develop new training protocols to develop and enhance operator skills with automated system
These challenges are best met if we include modeling higher cognitive functions, such as attention, memory, learning, and multi-tasking as part of our analysis process. The proposed IPM framework in this paper represents a tool to examine and validate next generation control room design.

\section{A. Advancement of Human Reliability Analysis}

A limitation of current HRA methods is the lack of data upon which to generate reliable probability estimates of risks associated with advanced design. Many HRA methods utilize estimates that are derived from data sources with high uncertainty, performance with conventional equipment or depend upon expert judgments that may differ as a function of the experts selected [7]. Also, as a simplifying assumption, current HRA methods treat PSFs as independent (or additive), whereas the consensus in the psychological literature places PSFs as interactive (or multiplicative).

The IPM framework can avoid the shortcomings of applying an HRA quantification method in a poorly suited domain or utilizing expert opinion to arrive at the human contribution to the risk of an event. Instead, scripting an IPM scenario that closely matches the event, it is possible to generate simulation runs with the virtual crew and to have the detailed cognitive model drive behavior in an applicable, i.e., multiplicative fashion consistent with the behavioral sciences literature. The output from the IPM simulation has the potential to increase the veracity of risk estimation.

As a first step we will be integrating the, SPAR-H HRA method developed at the INL for the US Nuclear Regulatory Commission with the IPM framework. This will allow: 1) data generation - running thousands of simulated trials to obtain the improved probability estimates, 2) examination of the dependency between different PSFs - manipulating different PSF variables in simulated trials (e.g., high work-load with little time vs. high work-load with extra time), and 3) the coupling of both retrospective analysis of past events with predictive analysis of possible future events

\section{B. Tool to Examine Next-Generation Reactors}

Next generation reactors will require more automated and highly sophisticated systems that potentially supervise and control multi-modular plants. Currently, little is known to how to interface such complex system within the limits of a staffing model. For instance, which staffing approach would be appropriate, a single crew for each reactor at a multi unit plant or decentralized functional crew for multiple reactors? As an assessment tool, IPM can evaluate staffing approaches by simulating crew performance under 
different contextual situations (e.g., normal, abnormal, and emergency conditions).

Designing system interfaces for advance automation is still an uncertain business. For instance, determining which information should be presented to operators without their initiative versus information that would need operator request, how information updates and types are prioritized, and who are given responsibility of information control under off-normal or unanticipated events? Furthermore, a critical need associated with performance is the operator's trust with automated systems. Ideally, an automated system should not direct operators to place too high or too low amount of trust in the system. High operator reliance on automated systems has been demonstrated to induce both error of commission (e.g., following automated system directions to commit incorrect actions) as well as errors of omission (e.g., failing to take action when called upon, that is , overly relying on the automated system to detect anomalies and take action) [8]. Based upon cognitive theories and models, the IPM can stimulate human performance to inspect the appropriateness of different interface designs as well as running simulated trials to better understand how operators acquire trust.

\section{Certification o fRreduced Staffing Levels in Control Rooms}

Currently regulated staffing levels in plant control rooms are based on the requirements of contemporary reactor designs. With the advent of next-generation reactor and control room designs, with a potentially greater emphasis on passive safety systems and autonomously regulated control systems, the role of the control room operators is significantly changed $[9,10]$. These updated control room designs will likely decrease the number of simultaneous control room and plant staff required to carry out the safe operation of the plant. Utilities and regulators are actively seeking ways to certify that reduced staff can perform all required plant operations within safe human performance levels [11] . IPM can play a role in evaluating the impact of different staffing strategies on plant performance.

\section{High-Fidelity Training}

The case-based learning approach matches standard examples against new cases or exemplars rather than abstract concepts (from Myers and Maulsby, http:/www.acypher.com/wwid/BackMatter/Glossary.ht $\underline{\mathrm{ml}}$, accessed May 2007) and has been claimed in the psychological and education literature to be an effective learning method. By review of the many possible situations and outcomes in examples Case based learning depicts the complexity and uncertainty of real world events, and allows analysts to gain greater understanding and to abstract principles from these examples. IPM's ability to generate numerous simulated scenarios (based on past real events or fictitious novel events) in a 3-D animated graphical representation is compatible with the case-base learning paradigm.

\section{SUMMARY / CONCLUSION}

Next generation control room systems will be more complex and automated leading to many human factors concerns that must be address before the full benefits of such a system can be realized. In this paper, we highlighted an approach to integrate three distinct modeling approaches, environmental models, manikins, and cognitive models, to obtain a unified performance modeling simulation environment suitable for evaluating next generation systems. Future research with the IPM should meet near-term concerns of staffing levels and associated roles, the impact of novel system designs and configurations, and shirts in performance variables such as workload that have the potential to change existing failure rates or introduce new failure modes.).

\section{DISCLAIMER}

This paper was prepared as an account of work sponsored by an agency of the United States Government. Neither the United States Government nor any agency thereof, nor any of their employees, makes any warranty, expressed or implied, or assumes any legal liability or responsibility for any third party's use, or the results of such use, of any information, apparatus, product, or process disclosed in this paper, or represents that its use by such third party would not infringe privately owned rights.

\section{REFERENCES}

[1] Lee, J.D. Human factors and ergonomics in automation design. In G. Salvendy (Eds.), Handbook of Human Factors and Ergonomics $3^{\text {rd }}$ Ed, pp. 1570-1596. New Jersey: John Wiley \& Sons, Inc, 2006.

[2] Abbott, K., Corker, K., Figarol, S., Hoekstra, J., Pritchett, A., \& Sheridan, T. Panel on human-automation interaction in the next generation air transportation system. Proceedings of the International Conference on Human-Computer Interaction in Aeronautics, Seattle, WA., 2006, 246-247.

[3] Gertman, D.I., \& Blackman, H.S. Human Reliability and Safety Analysis Data Handbook. New York: John Wiley \& Sons, Inc., 1994.

[4] Boring, R.L., \& Gertman, D.I. Advancing usability evaluation through human-reliability analysis. Proceedings of $\mathrm{HCI}$ International 2005, 2005.

[5] Kelley, T. D., Patton, D. \& Allender, L. Error rates in mental manipulation of spatial images. Perceptual and Motor Skills, 92, 2001, pp. 985-992.

[6] Dudenhoeffer, D., Permann, M.R., \& Manic, M. CIMS: A framework for infrastructure interdependency modeling and analysis. Proceedings of the 2006 Winter Simulations Conference, 2006. 
[7] Boring, R.L., Gertman, D.I., Joe, J.C., Marble, J.L., Blackwood, L.G., Blackman, H.S., \& Brady, B.M. Simplified expert elicitation guideline. Proceedings of the Eighth International Conference on Probabilistic Safety Assessment and Management, 2006.

[8] Skitka, L.J. Automation and automation bias. International Journal of Human-Computer Studies, 52, 2000, pp.701-717.

[9] Boring, R.L., Hugo, J., Richard, C.M., \& Dudenhoeffer, D.D Human-computer interaction for next-generation control rooms. CHI 2005 Conference Proceedings, 2005, pp. 206-207.

[10] Dudenhoeffer, D.D., Gertman, D.I., Boring, R.L., \& Marble, J.L. Transitioning to advanced human-machine interface technologies. Proceedings of the Fourth American Nuclear Society International Topical Meeting on Nuclear Power Plant Instrumentation, Controls, and Human-Machine Interface Technologies,2004, pp. 306-311.

[11] Persensky, J., Szabo, A., Plott, C., Engh, T., \& Barnes, V. Guidance for Assessing Exemption Requests from the Nuclear Power Plant Licensed Operator Staffing Requirements Specified in 10 CFR 50.54(m), NUREG-1791. Washington, DC: US Nuclear Regulatory Commission, 2005. 